\title{
Changes in leaf gas exchange and chlorophyll $a$ fluorescence on soybean plants supplied with silicon and infected by Cercospora sojina
}

\author{
Kelly Juliane Telles Nascimento ${ }^{1}$ | Daniel Debona ${ }^{2}$ | Danielle Rezende ${ }^{2}$ | Fábio Murilo \\ DaMatta $^{1}$ | Fabrício Ávila Rodrigues ${ }^{2}$ iD
}

\author{
${ }^{1}$ Departamento de Biologia \\ Vegetal, Universidade Federal de Viçosa \\ (UFV), Viçosa, Minas Gerais State, Brazil \\ ${ }^{2}$ Laboratório da Interação Planta- \\ Patógeno, Departamento de \\ Fitopatologia, UFV, Viçosa, Minas Gerais \\ State, Brazil
}

\section{Correspondence}

Fabrício Ávila Rodrigues, Departamento de Fitopatologia, Universidade Federal de Viçosa, Viçosa, Minas Gerais State, Brazil.

Email: fabricio@ufv.br

Funding information CAPES; CNPq; FAPEMIG

\begin{abstract}
Frogeye spot, caused by Cercospora sojina, is one of the major diseases causing yield losses in soybean. Considering the potential of silicon (Si) to attenuate the physiological impairments imposed by pathogens infection, this study investigated its effect on leaf gas exchange and chlorophyll (Chl) a fluorescence parameters as well as on the concentrations of photosynthetic pigments and carbohydrate pools on soybean plants from cultivars Bossier and Conquista (susceptible and resistant to frogeye spot, respectively) grown in hydroponic culture containing 0 or $2 \mathrm{mM} \mathrm{Si} \mathrm{(-Si} \mathrm{and}+\mathrm{Si}$ plants, respectively) that were noninoculated or inoculated with C. sojina. Plants from cultivar Bossier were more susceptible to frogeye spot compared to cultivar Conquista regardless of Si supply. Frogeye spot severity increased by Si supply regardless of the cultivar. There were no changes in the physiological parameters for noninoculated + Si plants. Even though the susceptibility of plants from cultivar Bossier to frogeye spot increased by Si supply, they showed lower values for the leaf gas exchange parameters, photochemical efficiency and concentration of photosynthetic pigments. The impairments imposed by $C$. sojina infection on the physiology of plants from cultivar Conquista were governed chiefly by reductions in stomatal conductance regardless of Si supply. The increase in hexose concentration for inoculated plants of the two cultivars was associated with their resistance to frogeye spot. Considering that the increased susceptibility of +Si plants from cultivar Conquista did not result in physiological impairments, it is plausible to rule out that the lower photosynthetic efficiency of plants from cultivar Bossier occurred due to a sharp reduction in the photosynthetically active leaf tissue.

KEYWORDS

chlorophyll $a$ fluorescence, frogeye spot, Glycine max, photosynthesis
\end{abstract}

\section{1 | INTRODUCTION}

Frogeye leaf spot (FLS), caused by the fungus Cercospora sojina K. Hara, is considered one of the most destructive foliar diseases affecting soybean plants, particularly during their reproductive growth stage (Mian, Missaoui, Walker, Phillips, \& Boerma, 2008). Significant yield losses of soybean ranging from $10 \%$ to $60 \%$ have been attributed to FLS under hot and humid growing conditions (Mian, Missaoui, Walker, Phillips, \& Boerma, 2008). On leaves, FLS symptoms begin as small water-soaked spots; as lesions expand, they 
develop a bright-brown centre surrounded by reddish-purple margins on the adaxial leaf surface while on the abaxial leaf surface lesions are grey with intense fungus sporulation (Almeida et al., 2005). Lesions coalescence gives the lesions an irregular shape (Almeida et al., 2005). Water-soaked lesions evolving into dark-brown circular lesions on stem and pods and brown to grey spots of different sizes have also been noticed (Almeida et al., 2005). Great reduction on soybean yield caused by frogeye spot has been reported in warm and humid growing regions of Argentina, Brazil, China, Nigeria and southern United States (Scandiani et al., 2012; Zhang, 2012). The decrease on soybean yield is linked with a reduction in the active photosynthetic area of leaves containing several necrotic lesions surrounded by chlorotic halo as a consequence of the nonselective toxins secreted by the fungus and also to the premature defoliation (Kim, Lee, Kim, Kim, \& Kim, 2011; Mian et al., 2008).

Reduction in photosynthesis is one of the most critical factors that explain the yield losses caused by pathogens infection (Kumar et al., 2013). There are many reports about the negative effect of pathogens of different lifestyles on photosynthesis (Bassanezi, Amorim, Bergamin Filho, \& Berger, 2002; Bastiaans \& Roumen, 1993; Bilgin, Zavala, Steven, Clough, \& Ort, 2010; Dallagnol, Rodrigues, Chaves, Vale, \& DaMatta, 2013; Kumar et al., 2013; Resende et al., 2012). The decrease in photosynthesis resulting from pathogens infection can be due to changes on stomatal and mesophyll resistance to the $\mathrm{CO}_{2}$ influx, on biochemical reactions associated with photosynthesis, on chloroplast structure and on the repression of genes involved in the primary metabolism (Bilgin et al., 2010; Pinkard \& Mohammed, 2006).

Notably, changes in the photosynthetic apparatus of plants infected by pathogens can be detected via alterations in the chlorophyll (Chl) a fluorescence emission kinetics (Alves, Guimarães, Chaves, DaMatta, \& Alfenas, 2011; Berger, Sinha, \& Roitsch, 2007; Gao et al., 2011; Rahoutei, García-Luque, \& Barón, 2000). Reduction in photosynthesis may decrease the availability of carbon skeletons for carbohydrates metabolism and also for the production of defencerelated compounds that help the plants to counteract the infection by pathogens (Bispo, Araujo, Ávila, DaMatta, \& Rodrigues, 2016). The rapid synthesis of secondary metabolites is of detrimental importance for host resistance against diseases and depends directly on the ability of the infected plants to mobilize carbon sources that are close or distal to the infection sites that demand energy expenditure (Guérard, Maillardb, Bréchet, Lieutiera, \& Dreyerb, 2007). Additional changes in carbon metabolism and consequential alterations in the source-sink patterns occur due to an increase in the demand for assimilates for mounting host defences (Berger et al., 2007).

Silicon (Si) plays a pivotal role in the nutritional status of a wide variety of monocot and dicot plant species and helps them, whether directly or indirectly, counteract abiotic and/or biotic stresses. However, the most notable effect of $\mathrm{Si}$ is the reduction in the intensities of a number of seedborne, soilborne and foliar diseases in many economically important crops that are caused by biotrophic, hemibiotrophic and necrotrophic plant pathogens (Debona, Rodrigues, \& Datnoff, 2017). Some diseases on soybean such as stem canker (Diaporthe phaseolorum f. sp. meridionalis), Asian soybean rust (Phakopsora pachyrhizi) and root rot (Phytophthora sojae) have been controlled by Si supply either through foliar spray or when plants were grown in nutrient solution containing Si (Debona et al., 2017; Rasoolizadeh et al., 2018). By contrast, Nascimento et al. $(2014,2016)$ noticed an increase in the susceptibility of soybean plants to FLS when supplied with Si. Deshmukh et al. (2013) identified Si transporters in soybean confirming that this species is able to uptake and translocate Si from roots to shoot. Some studies have demonstrated that the physiological limitations imposed by pathogens on their hosts are attenuated on plants supplied with Si. Resende et al. (2012) reported that sorghum plants inoculated with Colletotrichum sublineolum and supplied with $\mathrm{Si}$ showed lower decreases in the values of net carbon assimilation rate $(A)$, stomatal conductance to water vapour $\left(g_{s}\right)$ and transpiration rate $(E)$ in contrast to noninfected and non-Sisupplied plants. Dallagnol et al. (2013) demonstrated that $A$ values were less compromised due to an increase in foliar Si concentration (FSC) of rice plants infected by Bipolaris oryzae. Additionally, on rice plants supplied with $\mathrm{Si}$ and infected by Pyricularia oryzae, the values of the maximum photochemical efficiency of the photosystem II (PSII) $\left(F_{\mathrm{v}} / F_{\mathrm{m}}\right)$ were similar to the ones obtained from noninfected plants nonsupplied with Si (Gao et al., 2011).

Frogeye spot has been controlled using resistant cultivars and fungicides spray (Missaoui, Ha, Phillips, \& Boerma, 2007). The report of $C$. sojina isolates more sensitive to fungicides places frogeye spot in the spotlight of the plant breeders (Zhang, 2012). Therefore, the search for novel alternatives for frogeye spot control becomes primordial importance nowadays. Considering that Si provides many agronomic benefits to both monocot and dicot plants species, mainly related to the control of fungal diseases (Debona et al., 2017), it is hypothesized that Si could attenuate the negative effects imposed by $C$. sojina infection on the photosynthesis of soybean plants from two cultivars differing on their basal levels of resistance to frogeye spot.

\section{2 | MATERIAL AND METHODS}

\section{1 | Nutrient solution preparation}

The nutrient solution used to grow the soybean plants was prepared based on Clark (1975) with some modifications as follows: $1.04 \mathrm{mM} \mathrm{Ca}\left(\mathrm{NO}_{3}\right)_{2} \cdot 4 \mathrm{H}_{2} \mathrm{O}, 1 \mathrm{mM} \mathrm{NH}_{4} \mathrm{NO}_{3}, 0.8 \mathrm{mM} \mathrm{KNO}_{3}$, $0.069 \mathrm{mM} \quad \mathrm{KH}_{2} \mathrm{PO}_{4}, 0.931 \mathrm{mM} \mathrm{KCl}, 0.6 \mathrm{mM} \quad \mathrm{MgSO}_{4} .7 \mathrm{H}_{2} \mathrm{O}$, $19 \mu \mathrm{M} \mathrm{H} \mathrm{BO}_{3}, 2 \mu \mathrm{M} \mathrm{ZnSO} \cdot .7 \mathrm{H}_{2} \mathrm{O}, 0.5 \mu \mathrm{M} \mathrm{CuSO}_{4} \cdot 5 \mathrm{H}_{2} \mathrm{O}, 7 \mu \mathrm{M}$ $\mathrm{MnCl}_{2} \cdot 4 \mathrm{H}_{2} \mathrm{O}, 0.6 \mu \mathrm{M} \mathrm{Na}_{2} \mathrm{MoO}_{4} \cdot 4 \mathrm{H}_{2} \mathrm{O}, 60 \mu \mathrm{M} \mathrm{FeSO} \cdot .7 \mathrm{H}_{2} \mathrm{O}$ and $90 \mu \mathrm{M}$ ethylenediaminetetraacetic acid (EDTA). Potassium silicate was passed through a cation-exchange resin (Amberlite IR-120B, $\mathrm{H}^{+}$form; Sigma-Aldrich, São Paulo, Brazil) to obtain the monosilicic acid (Ma, Tamai, Ichii, \& Wu, 2002). The Si concentration of $2 \mathrm{mM}(+\mathrm{Si}$ ) was used to prepare the nutrient solution (Debona et al., 2017; Nascimento et al., 2014, 2016) to allow the highest Si uptake by plants during their growth. 


\section{2 | Plant growth}

Seeds from soybean cultivars Bossier and Conquista, susceptible and resistant to frogeye spot, respectively (Gravina, Sediyama, Martins, Moreira, \& Cruz, 2004), were surface sterilized in $10 \%$ $(\mathrm{v} / \mathrm{v}) \mathrm{NaOCl}$ for $3 \mathrm{~min}$, rinsed in sterilized water and germinated on distilled water-soaked germitest paper (Fischer Scientific Co.) in a germination chamber at $25^{\circ} \mathrm{C}$ for 6 days. The seedlings were transferred to plastic pots with one-fourth strength nutrient solution without Si. Two days after, seedlings (three per pot) were transferred to new plastic pots with $5 \mathrm{~L}$ of one strength nutrient solution with or without Si under continuous aeration. The nutrient solutions were replaced every 4 days or when the electrical conductivity was $85 \%$ of the initial value. The $\mathrm{pH}$ was checked daily and kept at 5.5 using $\mathrm{NaOH}$ or $\mathrm{HCl}(1 \mathrm{~N})$ solutions. Plants were grown in a greenhouse (temperature of $30 \pm 5^{\circ} \mathrm{C}$, relative humidity of $70 \pm 5 \%$ and natural photosynthetically active radiation (PAR) of $950 \pm$ ten $\mu \mathrm{mol}$ photons $\mathrm{m}^{-2} \mathrm{~s}^{-1}$ (measured at midday)).

\section{3 | Plant inoculation}

The isolate UFV-DFP Cs 01 of C. sojina was used to inoculate the plants. This isolate was preserved on stripes of filter paper placed into glass tubes containing silica gel at $4^{\circ} \mathrm{C}$. Two pieces of filter paper containing fungal mycelia were placed in Petri dishes containing potato dextrose agar (PDA). After 7 days, discs of the PDA containing fungal mycelia were transferred to new Petri dishes containing the V8 medium, which were maintained in a growth chamber at $25^{\circ} \mathrm{C}$ with a 12 -h photoperiod for 7 days. After this period, conidia were carefully removed from the Petri dishes after the addition of $10 \mathrm{~mL}$ water containing gelatin $1 \%(\mathrm{w} / \mathrm{v})$ using a soft bristle brush. The adaxial and abaxial leaf blades of plants (V6 growth stage, Fehr, Caviness, Burmood, \& Pennington, 1971) were inoculated with a conidial suspension $\left(4 \times 10^{4}\right.$ conidia $\left.\mathrm{mL}^{-1}\right)$ of $C$. sojina (20 mL per plant) until run-off using a VL Airbrush atomizer (Paasche Airbrush Co., Chicago, IL). After inoculation, plants were maintained in a plastic mist growth chamber (temperature of $25 \pm 2{ }^{\circ} \mathrm{C}$ (day) and $20 \pm 2{ }^{\circ} \mathrm{C}$ (night), relative humidity of $90 \pm 5 \%$, and natural PAR of $825 \pm 15 \mu \mathrm{mol}$ photons $\mathrm{m}^{-2} \mathrm{~s}^{-1}$ ) inside a greenhouse.

\subsection{Assessment of the FLS severity}

The sixth trifoliolate leaf, from base to top, of each plant was collected at 16 days after inoculation (dai), scanned at 600 dpi resolution, and the images obtained were processed to determine the FLS severity (FLSS) using the software QUANT (Resende et al., 2012).

\subsection{Determination of leaf gas exchange and $\mathrm{Chl} a$ fluorescence parameters}

The leaf gas exchange and the $\mathrm{Chl} a$ fluorescence parameters were assayed on the central leaflet of the sixth leaf of each plant per replication of each treatment at 8,14 and 16 dai. The net carbon assimilation rate $(A)$, stomatal conductance to water vapour $\left(g_{s}\right)$, internal $\mathrm{CO}_{2}$ concentration $\left(C_{i}\right)$ and transpiration rate $(E)$ were estimated from 09:00 to $12: 00 \mathrm{hr}$ (solar time) using a portable opensystem infrared gas analyzer (LI-6400, LI-COR Inc., Lincoln, NE, USA) under an external $\mathrm{CO}_{2}$ concentration of $400 \mu \mathrm{mol} \mathrm{mol}^{-1}$ air. All of the measurements were conducted under artificial and saturating photon irradiance $\left(1,000 \mu \mathrm{mol} \mathrm{m} \mathrm{s}^{-1}\right)$ at the leaf level. The Chl $a$ fluorescence parameters were determined using a fluorometer with a modulated pulse (MINI-PAM) (Walz, Effeltrich, Germany) on the same leaflets used for the leaf gas exchange parameters measurement. The leaflets, dark-adapted for $30 \mathrm{~min}$, were initially exposed to a weak far-red light pulse (1-2 $\left.\mu \mathrm{mol} \mathrm{m}{ }^{-2} \mathrm{~s}^{-1}\right)$ for the determination of the initial fluorescence $\left(F_{0}\right)$. Then, a saturating light pulse for $1 \mathrm{~s}$, with a PAR of $6,000 \mu \mathrm{mol}$ (photons) $\mathrm{m}^{-2} \mathrm{~s}^{-1}$, was applied to estimate the maximum emitted fluorescence $\left(F_{\mathrm{m}}\right)$. After, the leaflets were illuminated for $30 \mathrm{~s}$ with continuous actinic light $\left(1,000 \mu \mathrm{mol} \mathrm{m} \mathrm{m}^{-2} \mathrm{~s}^{-1}\right)$ to obtain the transient fluorescence $\left(F_{s}\right)$. Thereafter, light saturating pulses were applied to estimate the maximum fluorescence $\left(F_{m}{ }^{\prime}\right)$. The actinic light was turned off, and then, the far-red light was applied for the measurement of the $F_{0}$ from light-adapted plants $\left(F_{0}{ }^{\prime}\right)$. With these parameters, the maximum photosystem II (PSII) photochemical efficiency $\left(F_{v} / F_{m}\right)$, the quantum yield of electron transport ( $\Phi$ PSII) as well as the photochemical $\left(q_{\mathrm{P}}\right)$ and nonphotochemical (NPQ) quenching coefficients were estimated. For the calculation of the electron transport rate (ETR), it was considered that the PSI and PSII absorbed equal light amounts. The ETR was estimated as follows: ETR $=$ [PAR effectively intercepted by the leaf $] \times[$ foliar absortance] $\times$ ФPSII $\times 0.5$ (Stefanov \& Terashima, 2008).

\subsection{Determination of $\mathrm{Chl} a$ fluorescence images}

The Chl $a$ fluorescence images were obtained at 16 dai at the same leaflets used for the leaf gas exchange and $\mathrm{Chl} a$ fluorescence parameters measurements using an IMAGING-PAM fluorometer coupled with the Imaging Win software (Heinz Walz $\mathrm{GmbH}$, Effeltrich, Germany). The leaflets, dark-adapted for $30 \mathrm{~min}$, were fixed on a bracket at $18.5 \mathrm{~cm}$ from an IMAG-K4 chamber resulting images with the resolution at $640 \times 480$ pixels, which were obtained using the following parameters: measure light intensity 2 , frequency 1 , saturating pulse intensity 10 , gain 7 and damp 2 . The images from the $F_{v} / F_{m}, \Phi P S I I, a_{p}, N P Q$, and ETR parameters were obtained based on the $F_{0}, F_{m}, F_{0}{ }^{\prime}$ and $F_{m}{ }^{\prime}$ values according to Behr, Humbeck, Hause, Deising, and Wirsel (2010). The size of the sampled area on the leaflets was standardized to $2.8 \mathrm{~cm}$ width and $2.9 \mathrm{~cm}$ length with the resolution of $110 \times 160$ pixels.

\section{7 | Determination of $\mathrm{Chl} a, \mathrm{Chl} b$ and carotenoids concentrations}

The $\mathrm{Chl} a, \mathrm{Chl} b$ and carotenoids (CAR) were extracted using acetone $85 \%(\mathrm{v} / \mathrm{v})$, at $4{ }^{\circ} \mathrm{C}$, from leaf discs $\left(8 \mathrm{~mm}^{2}\right)$ sampled at 16 dai on the same leaflets used for the leaf gas exchange measurements and quantified according to Lichthenthaler (1987). 


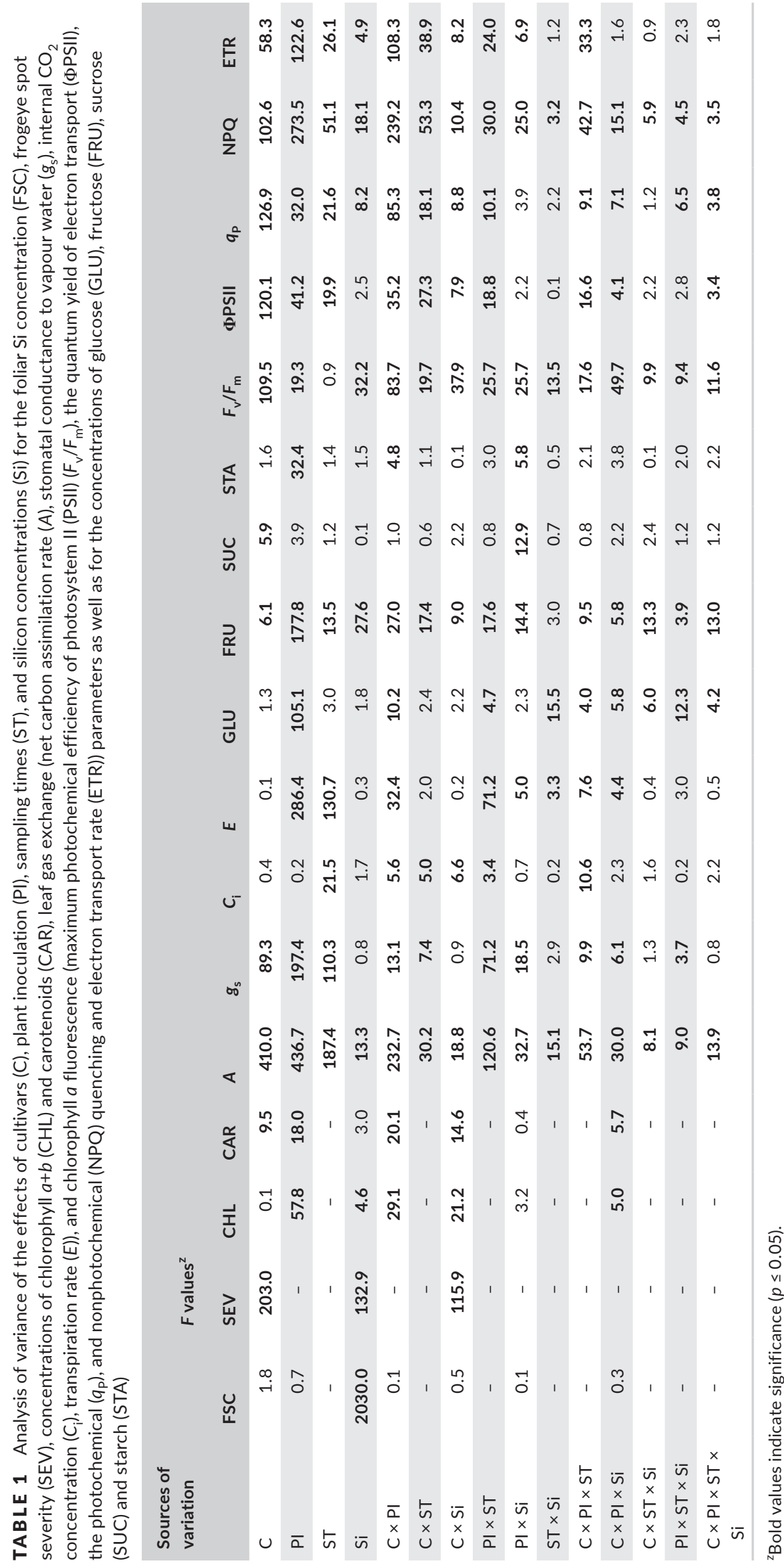




\section{8 | Determination of carbohydrate pools}

The fourth, fifth and sixth leaves, from top to base, of each plant per replication of each treatment were sampled at 8, 14 and 16 dai and used to determine the concentrations of glucose (GLU), fructose (FRU), sucrose (SUC) and starch (STA) according to Trethewey et al. (1998).

\section{9 | Determination of foliar Si concentration}

After determining the FLSS, the leaves were washed with deionized water, dried at $65^{\circ} \mathrm{C}$ for $72 \mathrm{hr}$ and ground in a Thomas-Wiley mill (Thomas Scientific, Swedesboro, NJ, USA) with a 40-mesh sieve. The foliar Si concentration (FSC) was colorimetrically determined using $0.1 \mathrm{~g}$ of alkali-digested dry leaf tissue (Resende et al., 2012).

\subsection{Experimental design and data analysis}

A $2 \times 2 \times 2$ factorial experiment with four replications consisting of two Si concentrations ( 0 or $2 \mathrm{mM}$, hereafter referred to $-\mathrm{Si}$ and $+\mathrm{Si}$ plants, respectively), two cultivars (Bossier and Conquista) and noninoculated or inoculated plants arranged in a completely randomized design was used to evaluate the FLSS and FSC. A $2 \times 2 \times 2$ factorial experiment (with four replications consisting of $-\mathrm{Si}$ or $+\mathrm{Si}$ plants, two cultivars and noninoculated or inoculated plants) was arranged in a completely randomized design and used to determine the leaf gas exchange and $\mathrm{Chl}$ a fluorescence parameters as well as the concentrations of photosynthetic pigments and carbohydrates. The experiments were repeated once. Data were subjected to analysis of variance (ANOVA) and the means compared by $F$ test $(p \leq 0.05)$ using the software SAS (v. 6.12; SAS Institute, Inc., Cary, NC, USA). For ANOVA, two experimental designs were considered. For FLSS and FSC, a $2 \times 2 \times 2$ factorial experiment consisting of $+\mathrm{Si}$ and $-\mathrm{Si}$ plants and two soybean cultivars was considered. For the leaf gas exchange and $\mathrm{Chl} a$ fluorescence parameters as well as the concentrations of total $\mathrm{Chl}(\mathrm{Chl} a+b), \mathrm{CAR}, \mathrm{GLU}, \mathrm{FRU}, \mathrm{SUC}$ and STA, a factorial experiment $2 \times 2 \times 2 \times 3$ (-Si or +Si plants, noninoculated or inoculated plants, two cultivars and three sampling times (8, 14 and 16 dai) was used. Each experimental unit consisted of a 5-L plastic pot containing three plants.

\section{RESULTS}

\section{$3.1 \mid$ FSC}

Only the factor Si concentration was significant (Table 1). The FSC was significantly higher for + Si plants than for - Si ones (Figure 1).

\section{$3.2 \mid$ FLSS}

The factors cultivars and Si concentrations and their interaction were significant for FLSS (Table 1). The FLSS symptoms were more expressive on plants from cultivar Conquista than from cultivar Bossier regardless of Si concentration (Figure 2). FLSS was significantly higher for + Si plants than for $-\mathrm{Si}$ ones regardless of the cultivar (Figure 2).

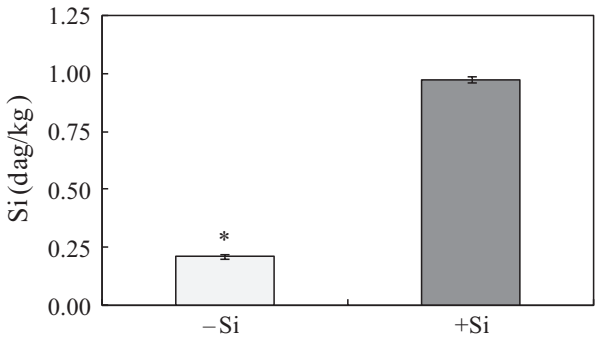

FIGURE 1 Foliar silicon (Si) concentration for soybean plants from cultivars Bossier and Conquista grown in hydroponic culture containing 0 or $2 \mathrm{mM} \mathrm{Si} \mathrm{(-Si} \mathrm{and}+\mathrm{Si}$, respectively). Means from $-\mathrm{Si}$ and $+\mathrm{Si}$ treatments followed by an asterisk $\left(^{*}\right)$ are significantly different by $F$ test $(p \leq 0.05)$. Bars represent the standard errors of the means

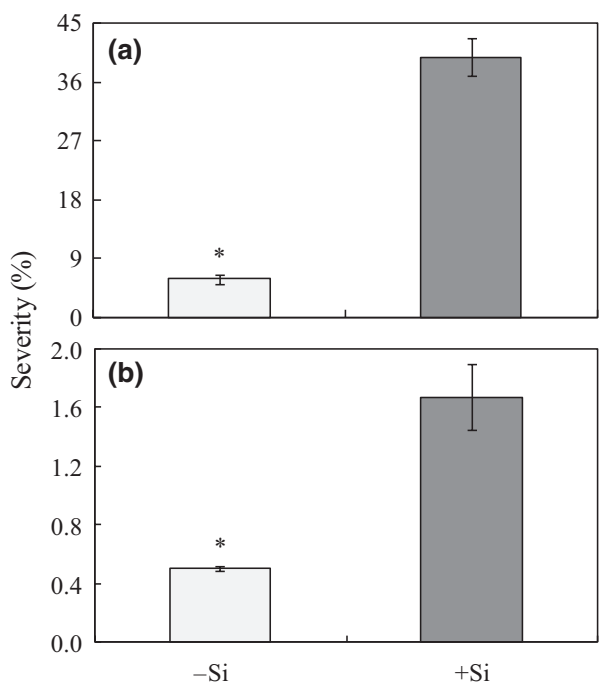

FIGURE 2 Frogeye spot severity on the leaves of soybean plants from cultivars Bossier (a) and Conquista (b) grown in hydroponic culture containing 0 or $2 \mathrm{mM}$ silicon ( $\mathrm{Si}$ ) (-Si and $+\mathrm{Si}$, respectively) at 16 days after inoculation with Cercospora sojina. Means from $-\mathrm{Si}$ and $+\mathrm{Si}$ treatments followed by an asterisk $\left({ }^{*}\right)$ are significantly different by $F$ test $(p \leq 0.05)$. Bars represent the standard errors of the means

\subsection{Leaf gas exchange and $\mathrm{Chl} a$ fluorescence parameters and carbohydrate concentrations}

The parameters $A, g_{s}, C_{i}, E, F_{v} / F_{m}$, DPSII, $q_{\mathrm{P}}, N P Q$ and ETR and the concentrations of GLU, FRU, SUC and STA were significantly influenced by at least one of the factors studied as well as for some of their interactions (Table 1). The interaction cultivars $\times$ plant inoculation $\times$ sampling times $\times \mathrm{Si}$ concentration was significant for A, $F_{v} / F_{m}$, ФPSII, $q_{\mathrm{p}}, \mathrm{NPQ}, \mathrm{ETR}, \mathrm{GLU}$ and FRU (Table 1 ). All of the above parameters were unaffected by $\mathrm{Si}$ for noninoculated plants of the two cultivars (Figures 3-5). For inoculated plants from cultivar Bossier, the A, E, $F_{\mathrm{v}} / F_{\mathrm{m}}, \Phi \mathrm{PSII}, q_{\mathrm{p}}$ and ETR values were lower while the NPQ values were higher at 14 and 16 dai; $g_{s}$ values were lower, and $C_{i}$ values were higher at 16 dai for $+S i$ plants than for -Si ones (Figures 3 and 4). The GLU concentration was high for 

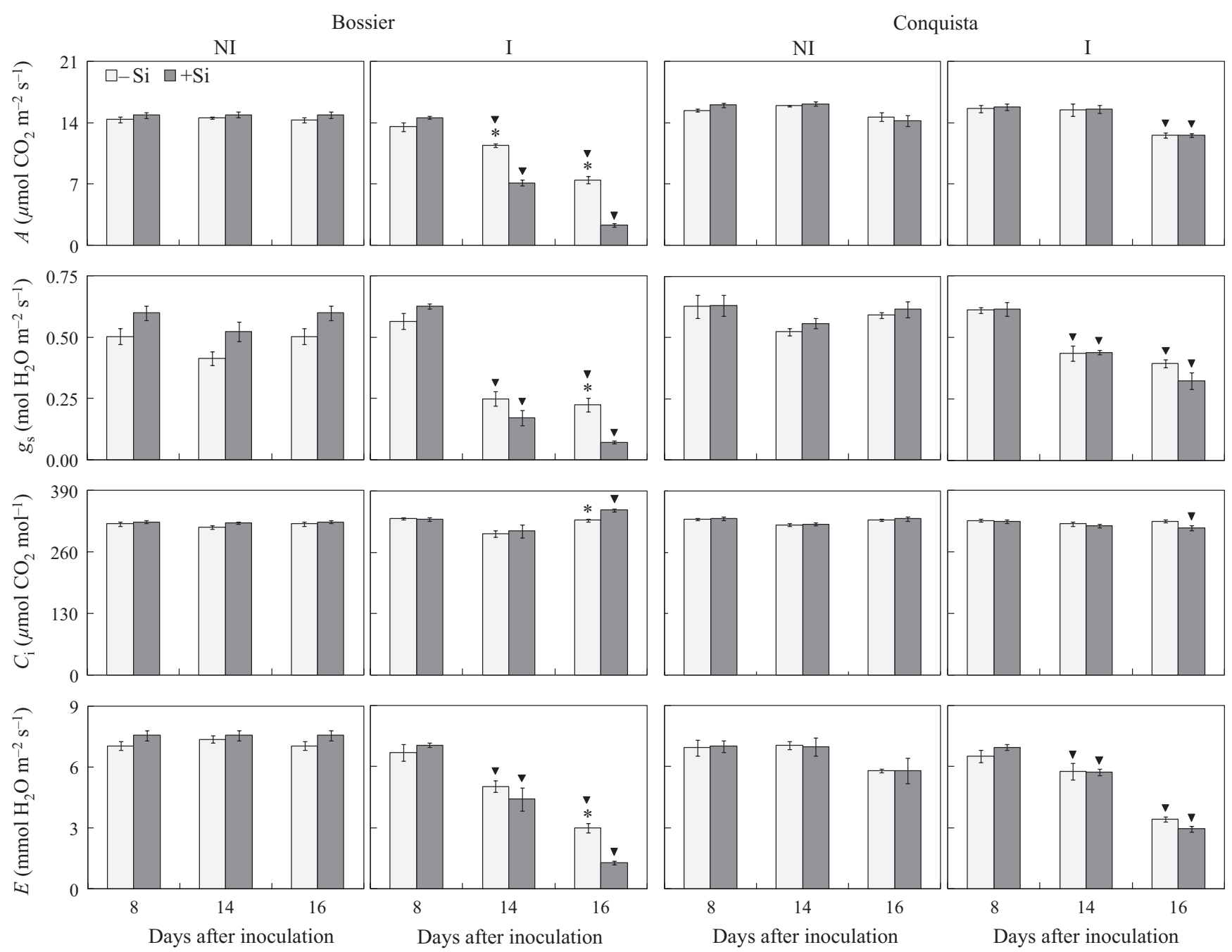

FIGURE 3 Net carbon assimilation rate $(A)$, stomatal conductance to vapour water $\left(g_{s}\right)$, internal $\mathrm{CO}_{2}$ concentration $\left(C_{i}\right)$ and transpiration rate $(E)$ determined in the leaves of soybean plants from cultivars Bossier and Conquista grown in hydroponic culture containing 0 or 2 mM silicon ( $\mathrm{Si})(-\mathrm{Si}$ and $+\mathrm{Si}$, respectively) and noninoculated (NI) or inoculated (I) with Cercospora sojina. Means from $-\mathrm{Si}$ and $+\mathrm{Si}$ treatments within evaluation time and $\mathrm{NI}$ or I treatments that are followed by an asterisk $\left({ }^{*}\right)$ are significantly different by $F$ test $(p \leq 0.05)$. Means from the NI and I treatments within evaluation time and for $-\mathrm{Si}$ or $+\mathrm{Si}$ treatments followed by an inverted triangle $(\nabla)$ are significantly different by $\mathrm{F}$ test $(p \leq 0.05)$. Bars represent the standard errors of the means

+ Si inoculated plants relative to their control counterparts at 8 dai (Figure 5). The FRU concentration was high for +Si plants than for -Si ones at 8 dai, but the opposite was observed at 14 and 16 dai (Figure 5). There were lower concentrations of SUC at 14 dai and of STA at 8 dai for +Si plants in comparison to -Si ones (Figure 5). There was no significant difference between inoculated $+\mathrm{Si}$ and inoculated -Si plants from cultivar Conquista for the leaf gas exchange and $\mathrm{Chl}$ a fluorescence parameters evaluated (Figure 4). FRU concentration was lower for + Si plants than for $-\mathrm{Si}$ ones regardless of sampling time (Figure 5). The concentrations of GLU and SUC at 16 dai and of STA at 8 dai were significantly higher for +Si plants in comparison to -Si ones (Figure 5). The inoculated plants from cultivar Bossier showed lower $A, g_{\mathrm{s}}, E, \Phi \mathrm{PSI}, q_{\mathrm{P}}$ and ETR values at 14 and 16 dai and higher NPQ values at 8,14 and 16 dai regardless of Si concentration (Figures 3 and 4). Inoculated
+Si plants had higher $C_{\mathrm{i}}$ values at 16 dai in comparison to the noninoculated ones (Figure 3). The GLU concentration was higher for inoculated plants than for the noninoculated ones regardless of $\mathrm{Si}$ concentration (Figure 5). High FRU concentration was observed for $-\mathrm{Si}$ inoculated plants at 8, 14 and 16 dai and for $+\mathrm{Si}$ plants inoculated plants at 8 dai relative to their control counterparts (Figure 5).

The $-\mathrm{Si}$ inoculated plants at 14 and 16 dai and the +Si inoculated plants at 16 dai showed lower STA concentration in comparison to their control counterparts (Figure 5). For inoculated plants from cultivar Conquista, there were reductions on $A$ values at 16 dai and on $g_{\mathrm{s}}$ and $E$ values at 14 and 16 dai regardless of Si concentration (Figure 3). Lower $C_{i}$ values were obtained for $+S i$ inoculated plants in comparison to noninoculated ones at 16 dai (Figure 3). The $\mathrm{Chl} a$ fluorescence parameters did not change for inoculated plants from 

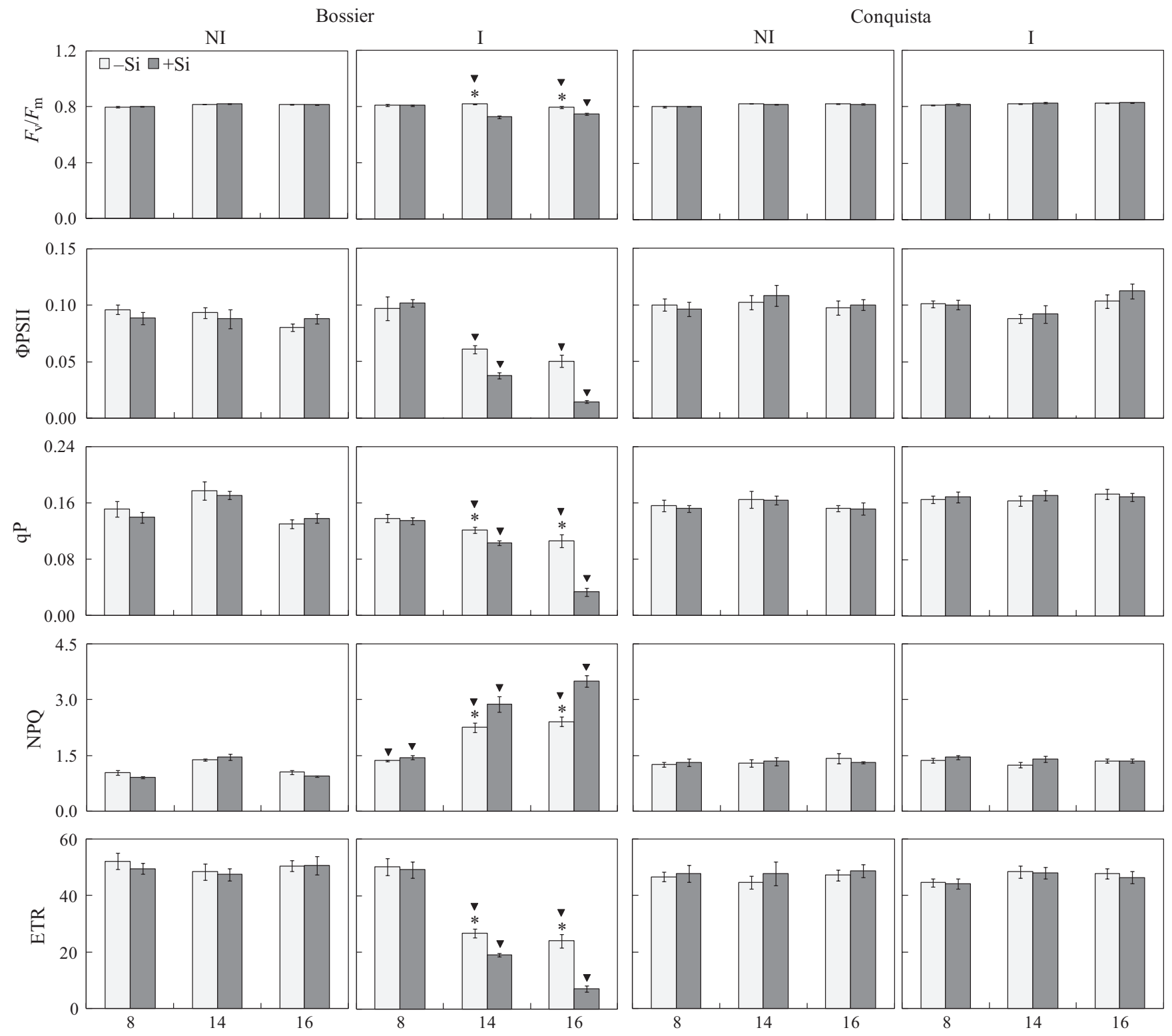

Days after inoculation

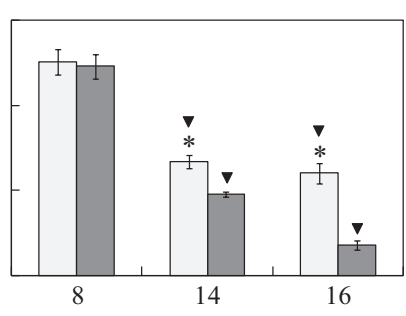

Days after inoculation

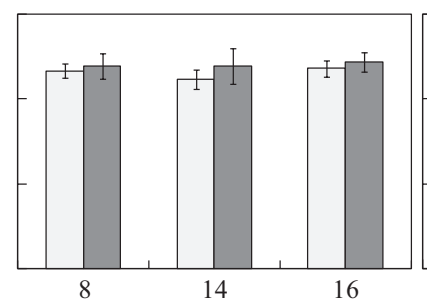

Days after inoculation

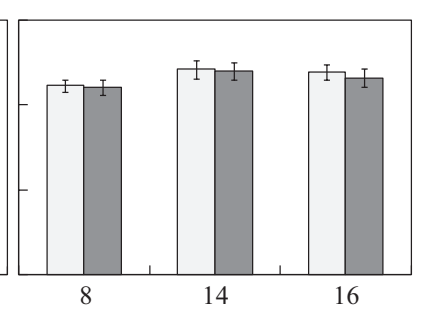

Days after inoculation

FIGURE 4 Maximum photochemical efficiency of photosystem II (PSII) $\left(F_{\mathrm{v}} / F_{\mathrm{m}}\right)$, quantum yield of electron transport ( $\Phi$ PSII), photochemical $\left(q_{\mathrm{p}}\right)$, nonphotochemical (NPQ) quenching and electron transport rate (ETR) determined in the leaves of soybean plants from cultivars Bossier and Conquista grown in hydroponic culture containing 0 or $2 \mathrm{mM}$ silicon (Si) (-Si and $+\mathrm{Si}$, respectively) and noninoculated (NI) or inoculated (I) with Cercospora sojina. Means from the $-\mathrm{Si}$ and +Si treatments within evaluation time and $\mathrm{NI}$ or I treatments followed by an asterisk $\left({ }^{*}\right)$ are significantly different by $\mathrm{F}$ test $(p \leq 0.05)$. Means from the $\mathrm{NI}$ and I treatments within evaluation time and for $-\mathrm{Si}$ or $+\mathrm{Si}$ treatments followed by an inverted triangle $(v)$ are significantly different by $F$ test $(p \leq 0.05)$. Bars represent the standard errors of the means

cultivar Conquista regardless of Si concentration (Figure 4). The FRU concentration was higher for $-\mathrm{Si}$ inoculated plants at 8,14 , and 16 dai and at 16 dai for + Si inoculated plants than for their control counterparts (Figure 5). The $+\mathrm{Si}$ inoculated plant, compared to their control counterparts, displayed lower STA concentrations at 8, 14 and 16 dai and lower SUC concentration at 8 and 16 dai, but higher GLU concentration at 8 dai (Figure 5). The -Si inoculated plants had high GLU concentration at 8 and 16 dai followed by a decrease at 14 dai relative to their control counterparts (Figure 5).

\subsection{Concentrations of $\mathrm{Chl} a+b$ and CAR}

Alone, the factor plant inoculation was more important to explain the variations in the concentrations of $a+b$ and CAR (Table 1). The interaction cultivars $\times$ plant inoculation $\times \mathrm{Si}$ concentrations was significant for the concentrations of $\mathrm{Chl} a+b$ and CAR (Table 1). For noninoculated plants from the two cultivars, the concentrations of $\mathrm{Chl} a+b$ and CAR were unaffected by Si (Figure 6). However, for inoculated plants from cultivar Bossier, lower concentrations 

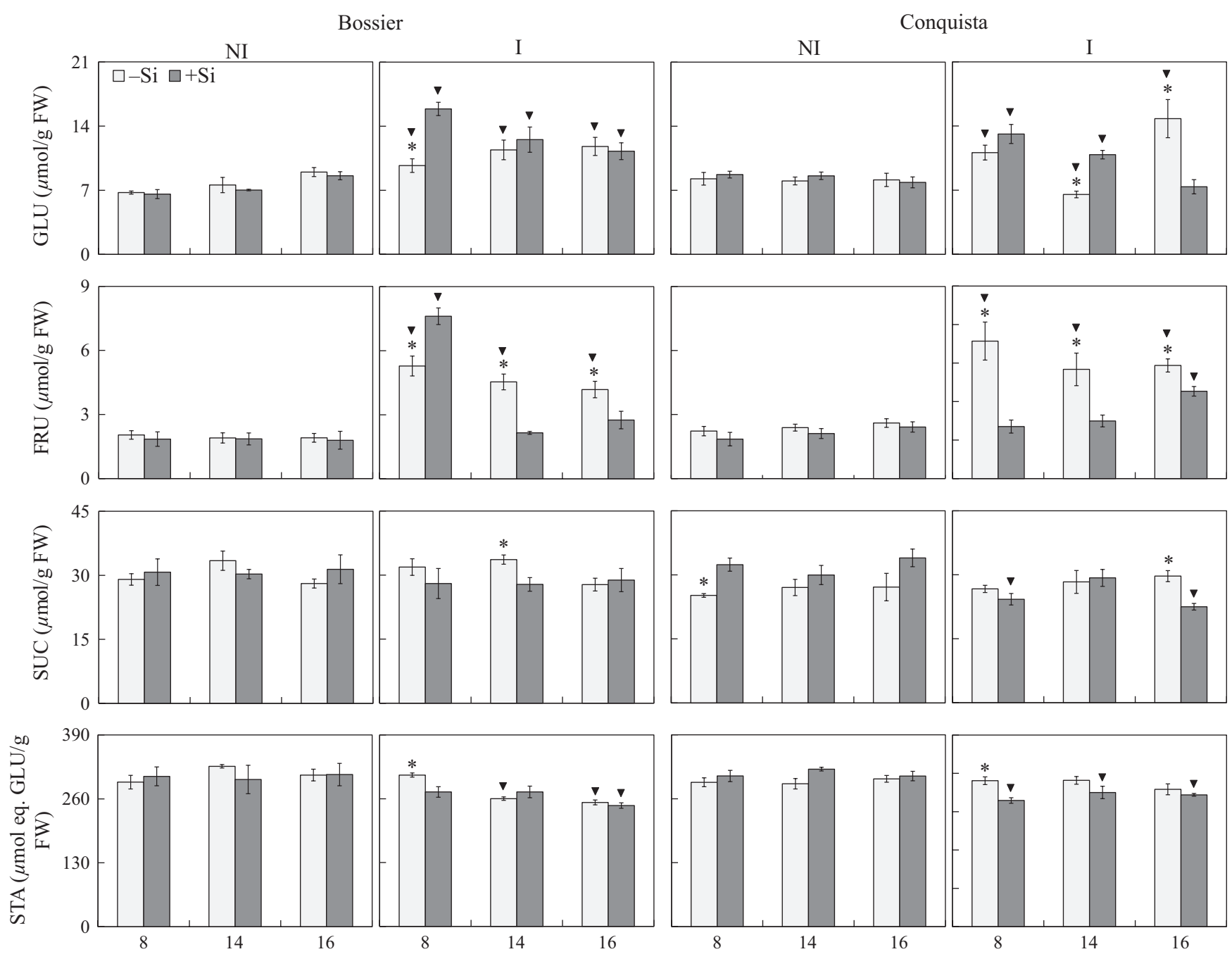

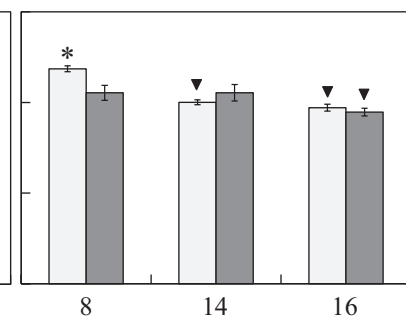

Days after inoculation

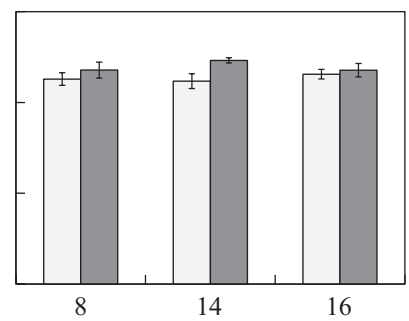

Days after inoculation

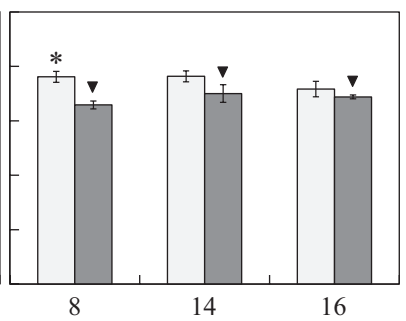

Days after inoculation

FIGURE 5 Concentrations of glucose (GLU), fructose (FRU), sucrose (SUC) and starch (STA) determined in the leaves of soybean plants from cultivars Bossier and Conquista grown in hydroponic culture containing 0 or $2 \mathrm{mM}$ silicon ( $\mathrm{Si}$ ) (-Si and $+\mathrm{Si}$, respectively) and noninoculated (NI) or inoculated (I) with Cercospora sojina. Means from the -Si and +Si treatments within evaluation time and $\mathrm{NI}$ or I treatments followed by an asterisk $(*)$ are significantly different by $F$ test $(p \leq 0.05)$. Means from the $\mathrm{NI}$ and I treatments within evaluation time and for $-\mathrm{Si}$ or $+\mathrm{Si}$ treatments followed by an inverted triangle $(v)$ are significantly different by $F$ test $(p \leq 0.05)$. Bars represent the standard errors of the means. FW = fresh weight

of $\mathrm{Chl} a+b$ and CAR were found for + Si plants than for $-\mathrm{Si}$ ones (Figure 6). Lower concentrations of $\mathrm{Chl} a+b$ and CAR were obtained for inoculated plants from cultivar Bossier in comparison to their control counterparts (Figure 6).

\subsection{Images of Chl $a$ fluorescence}

For noninoculated plants from both cultivars, the standard of colours for the fluorescence images of the parameters $F_{\mathrm{v}} / F_{\mathrm{m}}, q_{\mathrm{p}}$, NPQ and ETR did not qualitatively differ between $-\mathrm{Si}$ and $+\mathrm{Si}$ treatments (Figures 7 and 8). The changes on the images of the $F_{v} / F_{m}$, ФPSII, $q_{\mathrm{P}}$, ETR and NPQ were more drastic for inoculated plants from cultivar Bossier regardless of $\mathrm{Si}$ concentration (Figure 7). For plants of this cultivar, there was the loss of their photosynthetic capacity as noticed for the brown-dark or dark colour for the $F_{\mathrm{v}} / F_{\mathrm{m}}, \Phi \mathrm{PSII}, q_{\mathrm{p}}, \mathrm{NPQ}$ and ETR parameters particularly for $+\mathrm{Si}$ plants (Figure 7). For plants from cultivar Conquista, there were no apparent changes in colour for the images of $\mathrm{Chl} a$ fluorescence parameters regardless of Si concentration (Figure 8).

\section{6 | Pearson correlation}

For cultivar Bossier, there was a positive correlation of $A$ with $g_{s}$, $E, F_{\mathrm{v}} / F_{\mathrm{m}}$, ФPSII, $q_{\mathrm{p}}$, ETR, Chl and CAR, but negative with $C_{\mathrm{i}}, \mathrm{NPQ}$, FSC and FLSS (Table 2). The $g_{s}$ was positively correlated with $E$ and negatively with FSC and FLSS. The $C_{i}$ was positively correlated with NPQ, FSC and FLSS and negatively with CHL and CAR. The $E$ was positively correlated with CAR and negatively with FSC and FLSS. There was a positive correlation of $F_{v} / F_{m}$ with $\Phi P S I$, $q_{\mathrm{P}}$, ETR, CHL and CAR and a negative correlation with NPQ, FSC, 

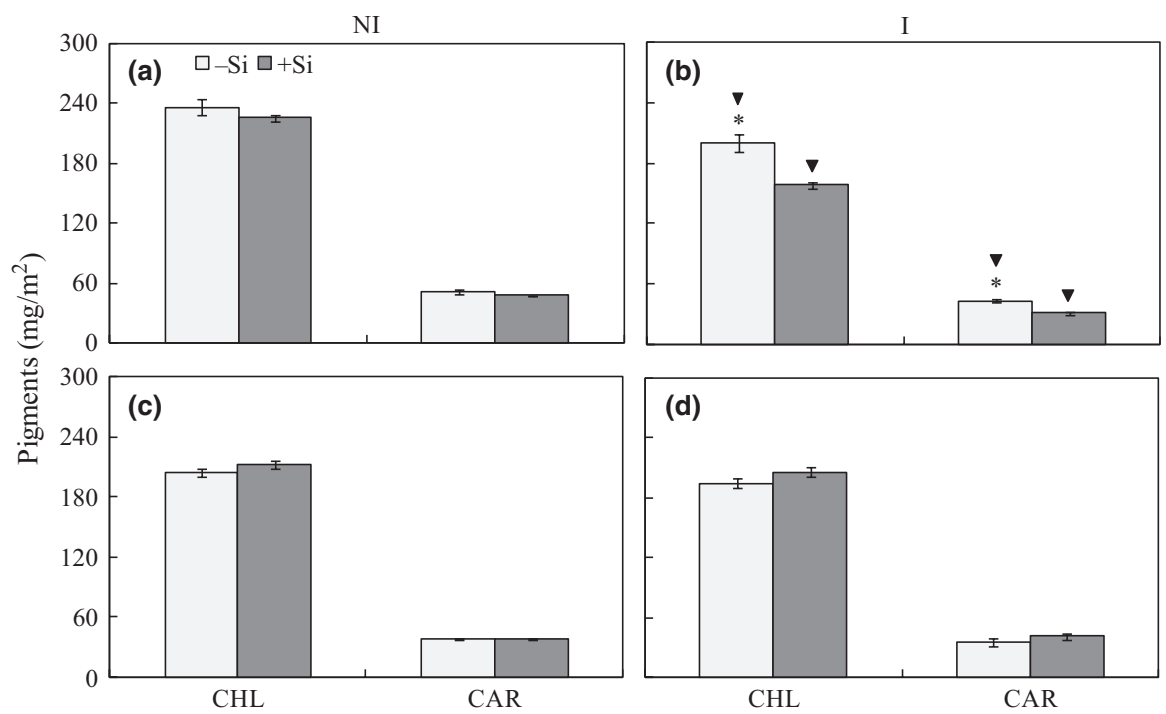

FIG URE 6 Concentrations of chlorophylls $a+b(\mathrm{CHL})$ and carotenoids (CAR) determined in the leaves of soybean plants from cultivars Bossier (a, b) and Conquista (c, d) grown in hydroponic culture containing 0 or $2 \mathrm{mM}$ silicon ( $\mathrm{Si}$ ) (-Si and $+\mathrm{Si}$, respectively) and noninoculated (NI) or inoculated (I) with Cercospora sojina. Means from the $-\mathrm{Si}$ and $+\mathrm{Si}$ treatments within evaluation time and $\mathrm{NI}$ or I treatments followed by an asterisk $\left({ }^{*}\right)$ are significantly different by $\mathrm{F}$ test $(p \leq 0.05)$. Means from the $\mathrm{NI}$ and I treatments within evaluation time and for $-\mathrm{Si}$ or $+\mathrm{Si}$ treatments that are followed by an inverted triangle $(\nabla)$ are significantly different by $F$ test $(p \leq 0.05)$. Bars represent the standard errors of the means

and FLSS. The $\Phi P S I I$ was positively correlated with $q_{\mathrm{p}}$, ETR and CAR, but negatively correlated with NPQ, FSC and FLSS. The $q_{\mathrm{P}}$ was positively correlated with ETR and CAR, but negatively correlated with NPQ, FSC and FLSS. The NPQ was positively correlated with FSC and FLSS, but negatively correlated with ETR, CHL and CAR. There was a positive correlation of ETR with $\mathrm{CHL}$ and CAR, of CAR with FRU, and of STA with FSC and FLSS. ETR, CHL, CAR and FRU were negatively correlated with FSC and FLSS. The GLU concentration was negatively correlated with STA concentration. For cultivar Conquista, there was positive correlation among $g_{s}$, $C_{\mathrm{i}}, \mathrm{E}, \mathrm{CHL}, \mathrm{FLSS}, \mathrm{GLU}, \mathrm{FRU}, \mathrm{SUC}, \mathrm{FRU}$ and SAC as well as between FSC and FLSS. There were negative correlations between $\mathrm{CHL}$ and GLU, FRU and FSC, and among GLU, SAC, FSC and FLSS (Table 2).

\section{4 | DISCUSSION}

The present results not only bring support to the concept soybean susceptibility to frogeye spot can be potentiated by $\mathrm{Si}$ (Nascimento et al., 2014, 2016), but also provide the first evidences at the physiological and biochemical levels. The susceptibility of soybean plants to frogeye spot potentiated by Si was linked to a reduction on their photosynthetic performance, especially for those of the most susceptible cultivar. The physiological parameters and the carbohydrate pools of noninoculated plants from the two cultivars tested, regardless of the basal level of resistance to frogeye spot, were not affected by Si. Resende et al. (2012) reported that sorghum plants noninfected with Colletotrichum sublineolum and supplied with $\mathrm{Si}$ did not show changes on $A, g_{s}$ and $E$ values in comparison to plants nonsupplied with $\mathrm{Si}$. Taken together, these results suggest that the effect of Si on the physiology of plant species such as sorghum and soybean is limited to situations where stresses are absent. Therefore, the increased soybean susceptibility to $C$. sojina accompanied by a decrease on photosynthesis due to Si cannot be linked to changes in the basal level of photosynthesis.

Some studies reported that lower $A$ values on plants infected by pathogens are intrinsically linked to their lifestyle (Alves et al., 2011; Bassanezi et al., 2002; Berger et al., 2007; Luque, Cohen, Savé, Biel, \& Álvarez, 1999; Resende et al., 2012; Vélez, Silva, Troncoso, \& Greslebin, 2012). In the present study, the negative effect of $C$. sojina infection on $A$ values from plants from cultivar Conquista was governed chiefly by a reduction in the $g_{s}$ values. However, the changes in the $g_{s}$ values were not enough to trigger changes in the $A$ values between $-\mathrm{Si}$ with $+\mathrm{Si}$ plants. Interestingly, the lower $C_{i}$ values for + Si plants were not related to decreases in $A$ values suggesting that the high frogeye spot severity on $+\mathrm{Si}$ plants from cultivar Conquista was not a crucial factor to damage their photosynthetic apparatus. Thus, for - $\mathrm{Si}$ and inoculated plants from cultivar Conquista, reductions in the $A$ values were governed chiefly by stomatal limitations and a lower concentration of photosynthetic pigments. Conversely, the susceptibility of plants from cultivar Bossier supplied with Si to frogeye spot was enhanced as noted by the remarkable decreases in the $A$ values due to stomatal and biochemical impairments besides a decrease on the concentration of photosynthetic pigments. Additional support for this conclusion is provided by the positive correlations of $A$ with $g_{s}$ and of $A$ with the concentration of photosynthetic pigments as well as the negative correlations of $A$ with $C_{i}$ and $A$ with the FSC. Noteworthy, the reductions in $g_{s}$ and $E$ values probably occurred by an intense loss of water on the leaf tissues infected by C. sojina. 
-Si NI

(a1)

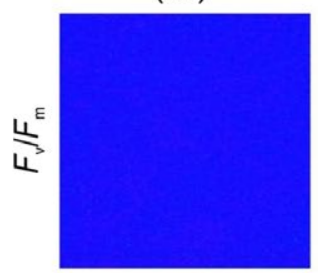

(b1)

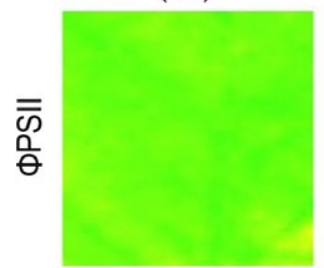

(c1)

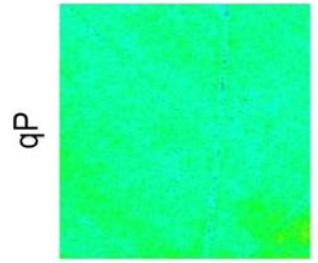

(d1)

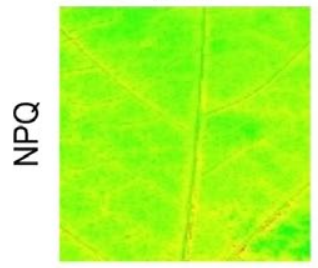

(e1)

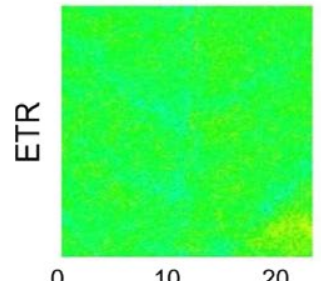

10

20
+Si NI

(a2)

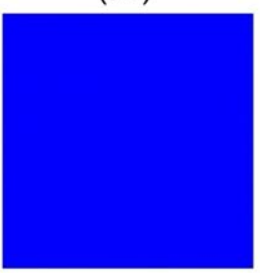

(b2)

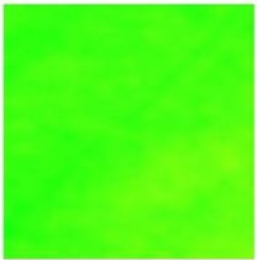

(c2)

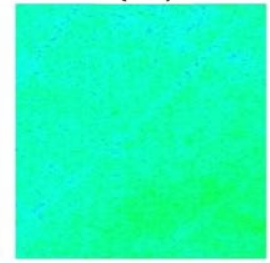

(d2)

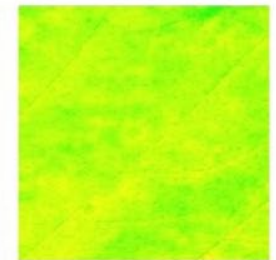

(e2)

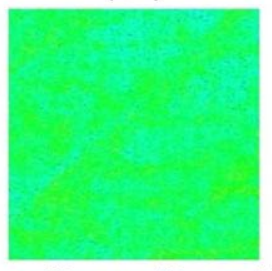

30
-Si

(a3)

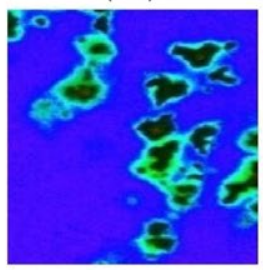

(b3)

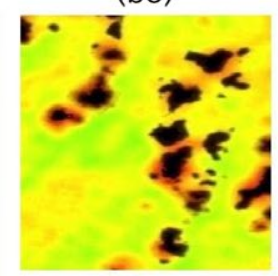

(c3)

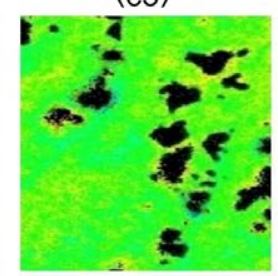

(d3)

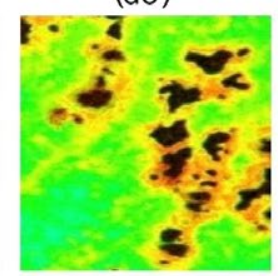

(e3)

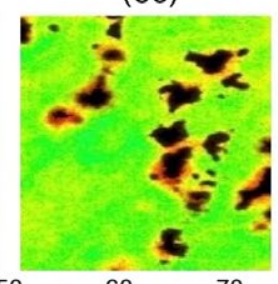

50
60
+Si I

(a4)

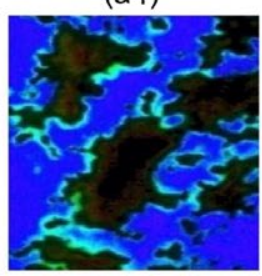

(b4)

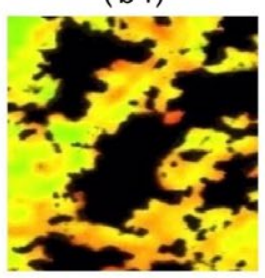

(c4)

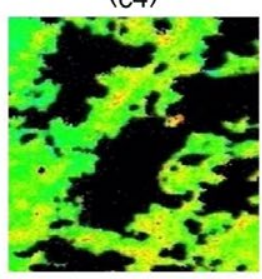

(d4)

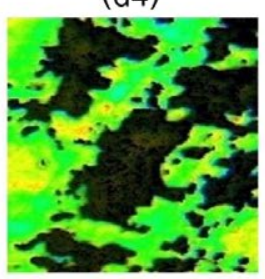

(e4)

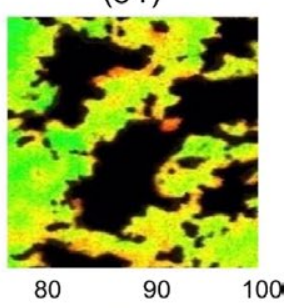

FIGURE 7 Images of chlorophyll $a$ fluorescence for maximum photochemical efficiency of photosystem II (PSII) $\left(F_{\mathrm{v}} / F_{\mathrm{m}}\right)$ (A1-A4), quantum yield of electron Transport (ФPSII) (B1-B4), photochemical $\left(a_{p}\right)(C 1-C 4)$, nonphotochemical quenching (NPQ) (D1-D4) and electron transport rate (ETR) (E1-E4) determined in the leaves of soybean plants from cultivar Bossier grown in hydroponic culture containing $0 \mathrm{mM}$ silicon (-Si) (A1, A3, B1, B3, C1, C3, D1, D3, E1 and E3) or $2 \mathrm{mM} \mathrm{Si}$ (+Si) (A2, A4, B2, B4, C2, C4, D2, D4, E2 and $\mathrm{E} 4)$ and noninoculated (NI) (A1, A2, B1, B2, C1, C2, D1, D2, E1 and E2) or at 16 days after inoculation with Cercospora sojina (A3, A4, B3, B4, C3, C4, D3, D4, E3 and E4) [Colour figure can be viewed at wileyonlinelibrary.com]
Considering that $C$. sojina aggressiveness is directly proportional to the release of nonselective toxins and hydrolytic enzymes and, consequently, an increase in the generation of reactive oxygen species (ROS), it is plausible to assume that the reduction in the concentration of photosynthetic pigments on plants from cultivar Bossier occurred due to an increase in their oxidative degradation potentiated by Si. Thus, decreases in A values for plants from cultivar Bossier may be explained, at least partially, by a reduction in the interception of solar radiation due to a lower concentration of photosynthetic pigments. In agreement with these results, tomato plants infected by Botrytis cinerea showed reduced chlorophylls concentration (Kuźniak \& Skłodowska, 2001). This decrease, similarly reported in the present study, was linked to an increase in the concentration of ROS in the leaflets of soybean plants supplied with Si and infected by C. sojina (Nascimento et al., 2016).
Overall, the infection of leaves of plants from cultivar Conquista by $C$. sojina did not trigger quantitative changes in the values of the $\mathrm{Chl}$ a fluorescence parameters and caused only marginal, if at all, changes in their images. These results lend additional support to explain why infection by $C$. sojina was not capable of damaging the photosynthetic apparatus of plants from cultivar Conquista. Conversely, the lower $A$ values on plants from cultivar Bossier infected by $C$. sojina were closely associated with the changes in $\mathrm{Chl} a$ fluorescence kinetics especially in the presence of $\mathrm{Si}$. These changes include lower and high values for $F_{v} / F_{m}$ and ETR, respectively, suggesting that infected plants displayed impairments on light capture which was consistent with the lower concentration of photosynthetic pigments. Furthermore, infection by $C$. sojina was related to the lower capacity of the reoxidation of the primary electron acceptor $\left(Q_{A}\right)$ based on the parameter $q_{\mathrm{P}}$, 


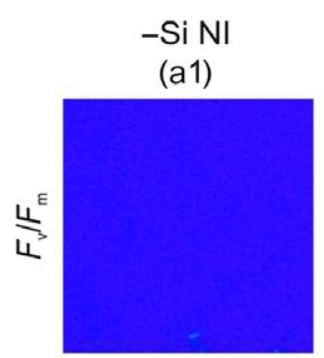

(b1)

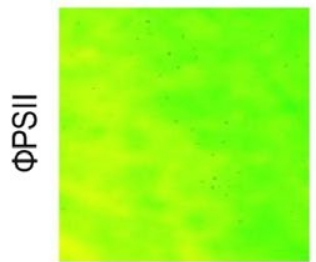

(c1)

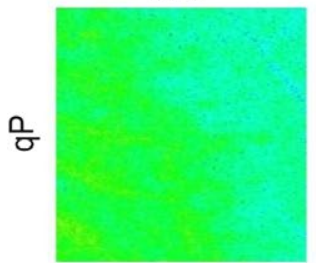

(d1)

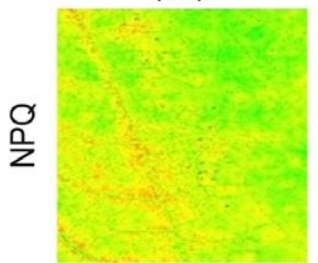

(e1)

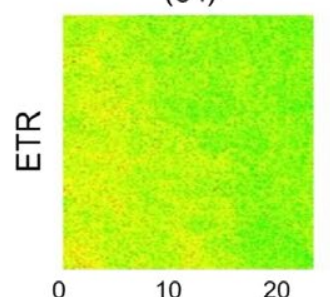

$+\mathrm{Si} \mathrm{NI}$

(a2)

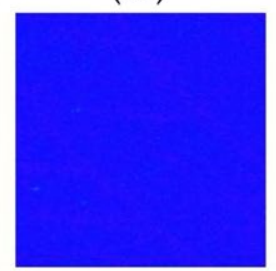

(b2)

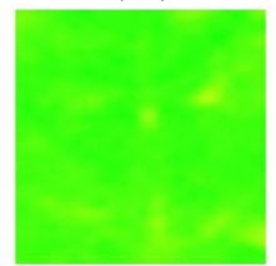

(c2)

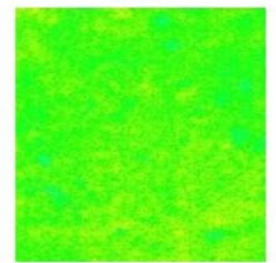

(d2)

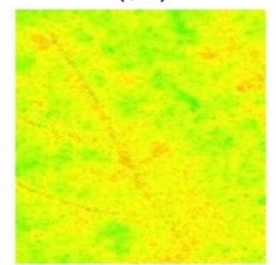

(e2)

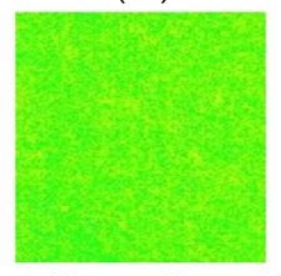

30
-Si I

(a3)

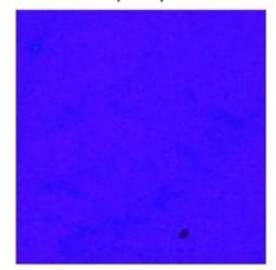

(b3)

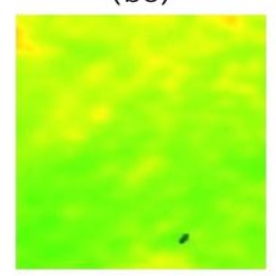

(c3)

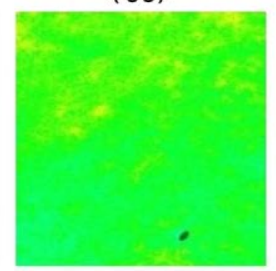

(d3)

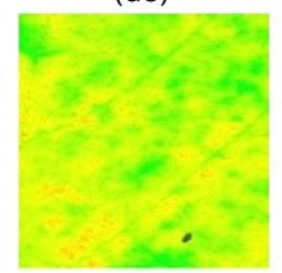

(e3)

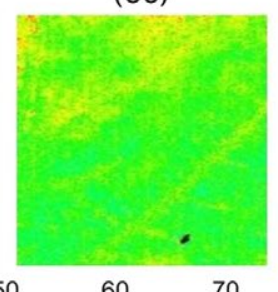

$+\mathrm{Si} I$

(a4)

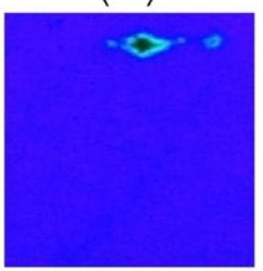

(b4)

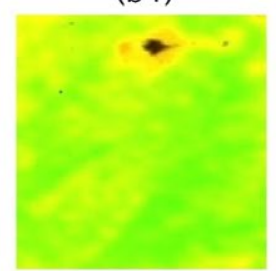

(c4)

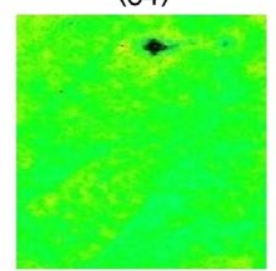

(d4)

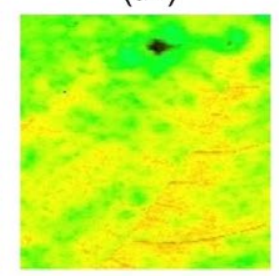

(e4)

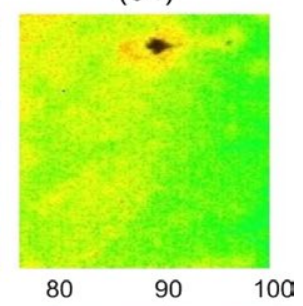

FIGURE 8 Images of chlorophyll a fluorescence for maximum photochemical efficiency of photosystem II (PSII) $\left(F_{v} / F_{m}\right)(A 1-A 4)$, quantum yield of electron transport (ФPSII) (B1-B4), photochemical $\left(q_{\mathrm{P}}\right)(\mathrm{C} 1-\mathrm{C} 4)$, nonphotochemical quenching (NPQ) (D1-D4) and electron transport rate (ETR) (E1-E4) determined in the leaves of soybean plants from cultivar Conquista grown in hydroponic culture containing $0 \mathrm{mM}$ silicon (-Si) (A1, A3, B1, B3, C1, C3, D1, D3, E1 and E3) or 2 mM Si (+Si) (A2, A4, B2, B4, C2, C4, D2, D4, E2 and E4) and noninoculated (NI) (A1, A2, B1, B2, C1, C2, D1, D2, E1 and E2) or at 16 days after inoculation with Cercospora sojina (A3, A4, B3, B4, C3, C4, D3, D4, E3 and E4) [Colour figure can be viewed at wileyonlinelibrary.com]

which estimates the ratio of the opened reaction centres of the PSII (Schreiber, Bilger, \& Neubauer, 1994). These data, together with lower $A$ values, suggest that the infection of plants from cultivar Bossier by $C$. sojina triggered an excess of excitation energy mainly when $\mathrm{Si}$ was available to them. Importantly, this excitation energy was unlike to have been dissipated as heat given that no increase in the NPQ values was noticed. As a final consequence, there was no extensive photooxidative damage to the photosynthetic apparatus. Additional support for this conclusion is given by the negative correlations of $A$ with $F_{\mathrm{v}} / F_{\mathrm{m}}, q_{\mathrm{p}}$ and ETR and positive correlation between $A$ with $\mathrm{NPQ}$. The images of $\mathrm{Chl} a$ fluorescence confirmed that the negative effect of $C$. sojina infection on the physiology of plants from cultivar Bossier was not restricted to the infection sites, but also extended to nonsymptomatic leaf tissue especially for plants supplied with $\mathrm{Si}$.

The negative effect of pathogens infection on the physiology of their hosts was extended to nonsymptomatic leaf tissue (Bastiaans, 


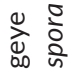

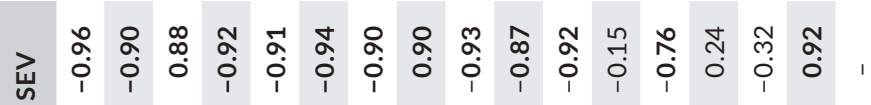

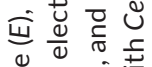

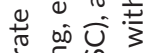

드은

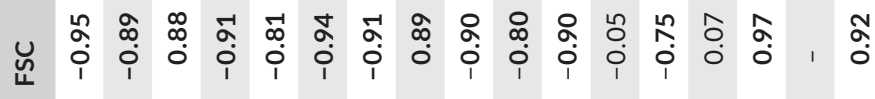

䓂

品

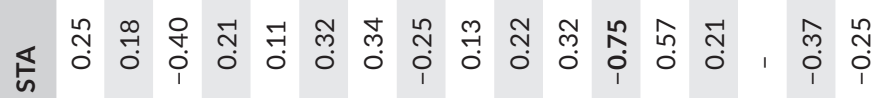

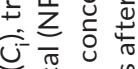

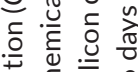

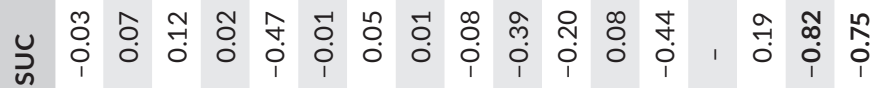

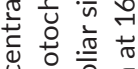

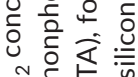

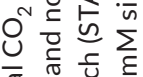

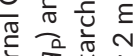

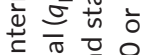

至

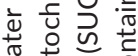

3 잉

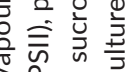

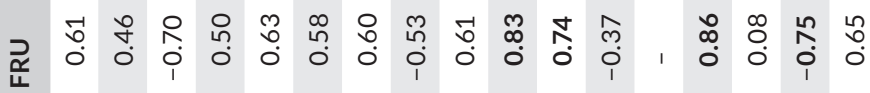

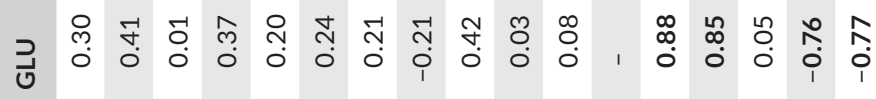

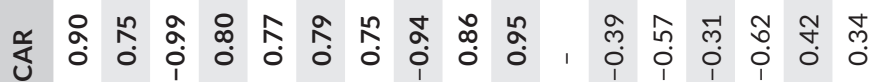

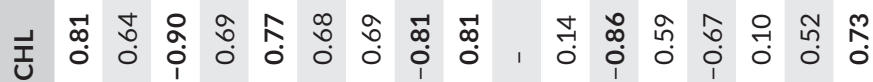

昰实

艺蓬

س

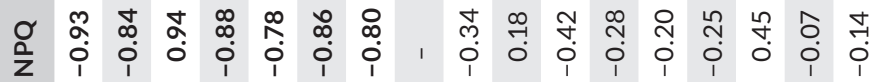

드의

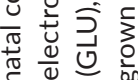

낭

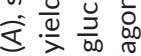

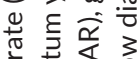

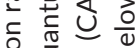

๙

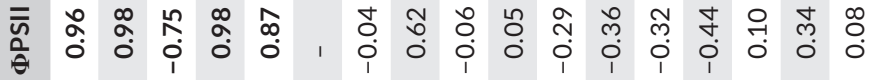

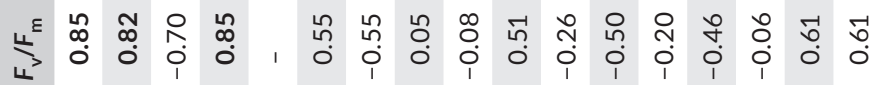

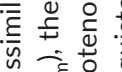

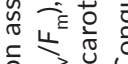

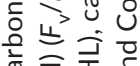

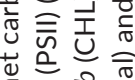

$\stackrel{\square}{=}$

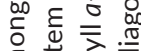

है ते

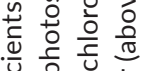

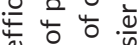

ठै

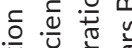

㼛说全要

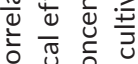

它

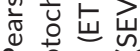

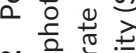

山

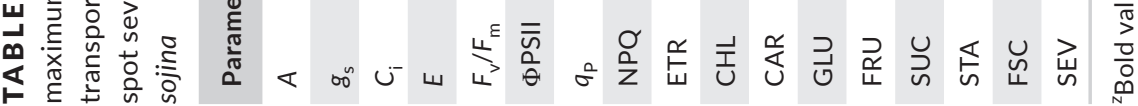


1991; Berger et al., 2007; Gruber, Kruger, \& McManus, 2012; Pinkard \& Mohammed, 2006; Rahoutei et al., 2000; Resende et al., 2012). However, in sharp contrast with the results of the present study, Gao et al. (2011) reported a positive effect of Si on the photochemical efficiency (evidenced by a lower decrease in the $F_{v} / F_{m}$ values and high concentration of photosynthetic pigments) for rice plants infected by $P$. oryzae. Similarly, the infection of rice and sorghum plants by $B$. oryzae and $C$. sublineolum, respectively, impaired photosynthesis, but for a lesser extent on plants supplied with Si (Dallagnol et al., 2013; Resende et al., 2012). However, considering that one of the effects of Si on the resistance of plants against pathogens infection is on the increase on $\mathrm{H}_{2} \mathrm{O}_{2}$ concentration (Shetty et al., 2011; Sun et al., 2010) and photorespiratory process (Van Bockhaven, De Vleesschauwer, \& Höfte, 2013), which also increase the $\mathrm{H}_{2} \mathrm{O}_{2}$ levels, it is believed that the infection by $\mathrm{C}$. sojina had benefited itself by the high ROS generated at the infection sites that culminated to a great impairment of the photosynthetic apparatus as previously reported by Nascimento et al. (2016).

In the present study, the reduction in A values was not correlated with the concentrations of GLU, FRU, SUC and STA regardless of cultivar used. However, considering that an increase in hexose concentration can trigger the activation of genes involved in host defence (Herbers, Meuwly, Frommer, Metraux, \& Sonnewald, 1996), such an increase for plants from cultivars Conquista and Bossier might suggest that the enhanced soluble carbohydrate pools may be a defence strategy mounted by soybean plants to counteract against $C$. sojina infection. This finding can be supported by the high concentration of hexoses and sucrose for plants from cultivar Conquista nonsupplied with $\mathrm{Si}$ at advanced stages of fungal infection. Additional support for this hypothesis is the negative correlations obtained among GLU, SUC, FSC and frogeye spot severity as well as the negative correlation between FRU and FSC for cultivar Conquista.

Considering that Si-increased susceptibility of soybean plants from cultivar Conquista to frogeye spot did not cause physiological impairments, it seems plausible to conclude that the lower photosynthetic efficiency of plants from cultivar Bossier was due to a reduced amount of photosynthetically active leaf tissue because of intense frogeye spot symptoms.

\section{ACKNOWLEDGEMENTS}

Professors Rodrigues and DaMatta thank the National Council for Scientific and Technological Development (CNPq) for their research fellowships. Mrs. Kelly Juliane Telles Nascimento was supported by CNPq. The authors thank Prof. Tuneo Sediyama and Mr. José Cupertino Pinheiro for providing the isolate of $C$. sojina. This study was supported by grants from CAPES, CNPq, and FAPEMIG to Prof. Rodrigues.

\section{CONFLICT OF INTEREST}

All authors declare no conflict of interest.

\section{ORCID}

Fabrício Ávila Rodrigues (iD http://orcid.org/0000-0002-3091-0000

\section{REFERENCES}

Almeida, A. M. R., Ferreira, J. T., Yorinori, J. F. V., Henning, A. A., Godoy, C. V., Costamilan, L. M., \& Meyer, M. C. (2005). Doenças da soja (Glycine max). In H. Kimati, L. Amorim, J. A. M. Rezende, A. Bergamin \& L. E. A. Camargo (Eds.), Doenças das Plantas Cultivadas (p. 574). Piracicaba, São Paulo: Editora Agronômica.

Alves, A. A., Guimarães, L. M. S., Chaves, A. R. M., DaMatta, F. M., \& Alfenas, A. C. (2011). Leaf gas exchange and chlorophyll $a$ fluorescence of Eucalyptus urophylla in response to Puccinia psidii infection. Acta Physiologiae Plantarum, 33, 1831-1839. https://doi.org/10.1007/ s11738-011-0722-z

Bassanezi, R. B., Amorim, L., Bergamin Filho, A., \& Berger, R. D. (2002). Gas exchange and emission of chlorophyll fluorescence during the monocycle of rust, angular leaf spot and anthracnose on bean leaves as a function of their trophic characteristics. Journal of Phytopathology, 150, 37-47. https://doi. org/10.1046/j.1439-0434.2002.00714.x

Bastiaans, L. (1991). Ratio between virtual and visual lesions size as a measure to describe reduction in leaf photosynthesis of rice due to leaf blast. Phytopathology, 81, 611-615. https://doi.org/10.1094/ Phyto-81-611

Bastiaans, L., \& Roumen, E. C. (1993). Effect on leaf photosynthesis rate by leaf blast for rice cultivars with different types and levels of resistance. Euphytica, 66, 81-87. https://doi.org/10.1007/BF00023511

Behr, M., Humbeck, K., Hause, G., Deising, H. B., \& Wirsel, S. G. R. (2010). The hemibiotroph Colletrotrichum graminicola locally induces photosynthetically active green islands but globally accelerates senescence on aging maize leaves. Molecular Plant-Microbe Interactions, 23, 879-892. https://doi.org/10.1094/MPMI-23-7-0879

Berger, S., Sinha, A. K., \& Roitsch, T. (2007). Plant physiology meets phytopathology: Plant primary metabolism and plant-pathogen interactions. Journal of Experimental Botany, 58, 4019-4026. https://doi. org/10.1093/jxb/erm298

Bilgin, D. D., Zavala, J. A., Steven, J. Z., Clough, S. J., \& Ort, D. R. (2010). Biotic stress globally downregulates photosynthesis genes. Plant, Cell \& Environment, 33, 1597-1613. https://doi. org/10.1111/j.1365-3040.2010.02167.x

Bispo, W. M. S., Araujo, L., Ávila, R. T., DaMatta, F. M., \& Rodrigues, F. A. (2016). Mango resistance against Ceratocystis fimbriata is impaired by local starch mobilization. Tropical Plant Pathology, 41, 225-236. https://doi.org/10.1007/s40858-016-0092-6

Clark, R. B. (1975). Characterization of phosphatase of intact maize roots. Journal Agricultural Food Chemistry, 23, 458-460. https://doi. org/10.1021/jf60199a002

Dallagnol, L. J., Rodrigues, F. A., Chaves, A. R. M., Vale, F. X. R., \& DaMatta, F. M. (2013). Photosynthesis and sugar concentration are impaired by the defective active silicon uptake in rice plants infected with Bipolaris oryzae. Plant Pathology, 62, 120-129. https://doi. org/10.1111/j.1365-3059.2012.02606.x

Debona, D., Rodrigues, F. A., \& Datnoff, L. E. (2017). Silicon's role in abiotic and biotic plant stresses. Annual Review of Phytopathology, 55, 85-107. https://doi.org/10.1146/annurev-phyto-080516-035312

Deshmukh, R. K., Vivancos, J., Guérin, V., Sonah, H., Labbé, C., Belzile, F., \& Bélanger, R. R. (2013). Identification and functional characterization of silicon transporters in soybean using comparative genomics of major intrinsic proteins in Arabidopsis and rice. Plant Molecular Biology, 83, 303-315. https://doi.org/10.1007/s11103-013-0087-3

Fehr, W. R., Caviness, C. E., Burmood, D. T., \& Pennington, J. S. (1971). Stage of development descriptions for soybeans, Glycine max 
(L.) Merrill. Crop Science, 11, 929-931. https://doi.org/10.2135/ cropsci1971.0011183X001100060051x

Gao, D., Cai, K., Chen, J., Luo, S., Zeng, R., \& Yang, J. Z. X. (2011). Silicon enhances photochemical efficiency and adjusts mineral nutrient absorption in Magnaporthe oryzae infected rice plants. Acta Physiologiae Plantarum, 33, 675-682. https://doi.org/10.1007/s11738-010-0588-5

Gravina, G. A., Sediyama, C. S., Martins, S. F., Moreira, M. A., \& Cruz, C. D. (2004). Multivariate analysis of combining ability for soybean resistance to Cercospora sojina Hara. Genetics and Molecular Biology, 27, 395-399. https://doi.org/10.1590/S1415-47572004000300015

Gruber, B. R., Kruger, E. L., \& McManus, P. S. (2012). Effects of cherry leaf spot on photosynthesis in tart cherry 'Montmorency' foliage. Phytopathology, 102, 656-661. https://doi.org/10.1094/PHYTO-12-11-0334

Guérard, N., Maillardb, P., Bréchet, C., Lieutiera, F., \& Dreyerb, E. (2007). Do trees use reserve or newly assimilated carbon for their defense reactions? A $13 \mathrm{C}$ labeling approach with young Scots pines inoculated with a bark-beetle-associated fungus (Ophiostoma brunneociliatum). Annals of Forest Science, 64, 601-608. https://doi.org/10.1051/ forest:2007038

Herbers, K., Meuwly, P., Frommer, W. B., Metraux, J. P., \& Sonnewald, U. (1996). Systemic acquired resistance mediated by the ectopic expression of invertase: Possible hexose sensing in the secretory pathway. The Plant Cell, 8(793), 803.

Kim, J. S., Lee, Y. S., Kim, S. K., Kim, K. D., \& Kim, J. W. (2011). Differential responses of soybean cultivars to Cercospora sojina isolates, the causal agent of frogeye leaf spot in Korea. The Plant Pathology Journal, 27, 183-186. https://doi.org/10.5423/PPJ.2011.27.2.183

Kumar, A., Guha, A., Bimolata, W., Reddy, A. R., Laha, G. S., Sundaram, R. M., ... Ghazi, I. A. (2013). Leaf gas exchange physiology in rice genotypes infected with bacterial blight: An attempt to link photosynthesis with disease severity and rice yield. Australian Journal of Crop Science, 7, 32-39.

Kuźniak, E., \& Skłodowska, M. (2001). Ascorbate, glutathione and related enzymes in chloroplasts of tomato leaves infected by Botrytis cinerea. Plant Science, 160, 723-731. https://doi.org/10.1016/ S0168-9452(00)00457-X

Lichthenthaler, H. K. (1987). Chlorophylls and carotenoids: Pigments of photosynthetic biomembranes. Methods in Enzymology, 148, 350382. https://doi.org/10.1016/0076-6879(87)48036-1

Luque, J., Cohen, M., Savé, R., Biel, C., \& Álvarez, I. F. (1999). Effects of three fungal pathogens on water relations, chlorophyll fluorescence and growth of Quercus suber L. Annals of Forest Science, 56, 19-26. https://doi.org/10.1051/forest:19990103

Ma, J. F., Tamai, K., Ichii, M., \& Wu, G. F. (2002). A rice mutant defective in Si uptake. Plant Physiology, 130, 2111-2117. https://doi.org/10.1104/ pp.010348

Mian, M. A. R., Missaoui, A. M., Walker, D. R., Phillips, D. V., \& Boerma, H. R. (2008). Frogeye leaf spot of soybean: A review and proposed race designations for isolates of Cercospora sojina Hara. Crop Science, 48, 14-24. https://doi.org/10.2135/cropsci2007.08.0432

Missaoui, A. M., Ha, B. K., Phillips, D. V., \& Boerma, H. R. (2007). Single nucleotide polymorphism detection of the Rcs3 gene for resistance to frogeye leaf spot in soybean. Crop Science, 47, 1681-1690. https:// doi.org/10.2135/cropsci2006.11.0711

Nascimento, K. J. T., Debona, D., França, S. K. S., Gonçalves, M. G. M., DaMatta, F. M., \& Rodrigues, F. A. (2014). Soybean resistance to Cercospora sojina infection is not enhanced by silicon. Phytopathology, 104, 1183-1191. https://doi.org/10.1094/PHYTO-02-14-0047-R

Nascimento, K. J. T., Debona, D., Silveira, P. R., Silva, L. C., DaMatta, F. M., \& Rodrigues, F. A. (2016). Silicon-induced changes in the antioxidant system reduce soybean resistance to frogeye leaf spot. Journal of Phytopathology, 164, 768-778. https://doi.org/10.1111/jph.12497

Pinkard, E. A., \& Mohammed, C. L. (2006). Photosynthesis of Eucalyptus globulus with Mycosphaerella leaf disease. New Phytologist, 170, 119127. https://doi.org/10.1111/j.1469-8137.2006.01645.x
Rahoutei, J., García-Luque, I., \& Barón, M. (2000). Inhibition of photosynthesis by viral infection: Effect on PSII structure and function. Physiologia Plantarum, 110, 286-292. https://doi. org/10.1034/j.1399-3054.2000.110220.x

Rasoolizadeh, A., Labbé, C., Sonah, H., Deshmukh, R. K., Belzile, F., Menzies, J. G., \& Bélanger, R. R. (2018). Silicon protects soybean plants against Phytophthora sojae by interfering with effector-receptor expression. BMC Plant Biology, 18, 97. https://doi.org/10.1186/ s12870-018-1312-7

Resende, R. S., Rodrigues, F. A., Cavatte, P. C., Martins, S. C. V., Moreira, W. R., Chaves, A. R. M., \& DaMatta, F. M. (2012). Leaf gas exchange and oxidative stress in sorghum plants supplied with silicon and infected by Colletotrichum sublineolum. Phytopathology, 102, 892-898. https://doi.org/10.1094/PHYTO-01-12-0014-R

Scandiani, M., Ferri, M., Ferrari, B., Carmona, M., Luque, A., \& Balatti, P. (2012). First report of races 11 and 12 of Cercospora sojina, the causal agent of soybean frogeye leaf spot, in Argentina. Plant Disease, 96, 1067. https://doi.org/10.1094/PDIS-02-12-0154-PDN

Schreiber, U., Bilger, W., \& Neubauer, C. (1994). Chlorophyll fluorescence as a nonintrusive indicator of rapid assessment of in vivo photosynthesis. In E. D. M. Schulze \& M. M. Caldwell (Eds.), Ecophysiology of photosynthesis (pp. 49-70). Berlin: Springer-Verlag.

Shetty, R., Fretté, X., Jensen, B., Shetty, N. P., Jensen, J. D., Jørgensen, H. J. L., ... Christensen, L. P. (2011). Silicon-induced changes in antifungal phenolic acids, flavonoids, and key phenylpropanoid pathway genes during the interaction between miniature roses and the biotrophic pathogen Podosphaera pannosa. Plant Physiology, 157, 2194-2205. https://doi.org/10.1104/pp.111.185215

Stefanov, D., \& Terashima, I. (2008). Non-photochemical loss in PSII in highand low light-grown leaves of Vicia faba quantified by several fluorescence parameter including $\mathrm{L}_{\mathrm{NP}}, F_{0} / \mathrm{F}_{\mathrm{m}}$, , a novel parameter. Physiologia Plantarum, 133, 327-338. https://doi.org/10.1111/j.1399-3054.2008.01077.x

Sun, W., Zhang, J., Fan, Q., Xu, G., Li, Z., \& Liang, Y. (2010). Siliconenhanced resistance to rice blast is attributed to silicon-mediated defence resistance and its role as physical barrier. European Journal Plant Pathology, 128, 39-49. https://doi.org/10.1007/s10658-010-9625-x

Trethewey, R. N., Geigenberger, P., Riedel, K., Hajirezaei, M. R., Sonnewald, U., Stitt, M., ... Willmitzer, L. (1998). Combined expression of glucokinase and invertase in potato tuber leads to a dramatic reduction in starch accumulation and a stimulation of glycolysis. The Plant Journal, 15, 109-118. https://doi. org/10.1046/j.1365-313X.1998.00190.x

Van Bockhaven, J., De Vleesschauwer, D., \& Höfte, M. (2013). Towards establishing broad-spectrum disease resistance in plants: Silicon leads the way. Journal of Experimental Botany, 64, 1281-1293. https:// doi.org/10.1093/jxb/ers329

Vélez, M. L., Silva, P. V., Troncoso, O. A., \& Greslebin, A. G. (2012). Alteration of physiological parameter of Austrocedrus chilensis by the pathogen Phytophthora austrocedrae. Plant Pathology, 61, 877-888. https://doi.org/10.1111/j.1365-3059.2011.02585.x

Zhang, G. (2012). Cercospora sojina: Over-winter survival and fungicide resistance (Dissertation). University of Illinois at Urbana-Champaign, Urbana, Illinois.

How to cite this article: Nascimento KJT, Debona D, Rezende D, DaMatta FM, Rodrigues FÁ. Changes in leaf gas exchange and chlorophyll $a$ fluorescence on soybean plants supplied with silicon and infected by Cercospora sojina. J Phytopathol. 2018;166:747-760. https://doi.org/10.1111/jph.12757 